\title{
EVASÃO NO IFMG- CAMPUS PIUMHI: ESTUDO DE CASO NO CURSO TÉCNICO SUBSEQUENTE EM EDIFICAÇÕES
}

\section{ARTIGO ORIGINAL}

SANTOS, Fernanda Aparecida Costa ${ }^{1}$

COSTA, Lavínia Apolyane ${ }^{2}$

COSTA, Susana Maria Oliveira ${ }^{3}$

FARIA, Ana Paula Aparecida de ${ }^{4}$

OLIVEIRA, Mariana Lara de ${ }^{5}$

SOARES, Denilson Junio Marques ${ }^{6}$

SANTOS, Fernanda Aparecida Costa. Et al. Evasão no IFMG- Campus Piumhi: Estudo de Caso no Curso Técnico Subsequente em Edificações. Revista Científica Multidisciplinar Núcleo do Conhecimento. Ano 05, Ed. 01, Vol. 07, pp. 6578. Janeiro de 2020. ISSN: 2448-0959, Link de acesso: https://www.nucleodoconhecimento.com.br/engenharia-civil/evasao-no-ifmg

\footnotetext{
${ }^{1}$ Graduanda em Engenharia Civil.

2 Graduanda em Engenharia Civil.

${ }^{3}$ Graduanda em Engenharia Civil.

${ }^{4}$ Graduanda em Engenharia Civil.

${ }^{5}$ Graduanda em Engenharia Civil.

${ }^{6}$ Doutorando do Programa de Pós-Graduação em Educação (PPGE) da Universidade Federal do Espírito Santo (UFES). Mestre em Estatística Aplicada e Biometria e Licenciado em Matemática pela Universidade Federal de Viçosa (UFV), com período sanduíche na Technische Universität München (TUM), Alemanha.
} 


\section{RESUMO}

O aumento nos índices de evasão escolar é um fenômeno cada vez mais frequente, que atinge a maior parte das instituições de ensino do Brasil e que deve ser objeto de estudo e discussão frequentemente, considerando seus impactos sociais e econômicos. Neste artigo, o objetivo é traçar o perfil dos estudantes evadidos do curso Técnico em Edificações, na modalidade subsequente, do IFMG - Campus Piumhi. Para isto, foi realizado um estudo analítico-descritivo, através de um levantamento de dados oriundos da secretaria acadêmica da instituição. Verificou-se que os estudantes evadidos, em sua maioria, eram homens, brancos, solteiros, oriundos da zona urbana e de escola pública, ingressos pelo vestibular, e cuja mediana das idades é de 27 anos. Também se realizou o teste Exato de Fisher, cujo resultado indicou que o tempo da conclusão do ensino médio era uma característica estaticamente significativa no processo de evasão, apontando para a necessidade de uma maior assistência acadêmica à esse grupo de estudantes, como o oferecimento de monitorias e cursos de nivelamento. As análises foram realizadas com o auxílio dos softwares Excel e R. Espera-se que este trabalho, embora introdutório, reflita em debates e discussões entre gestores, professores e demais profissionais da educação no âmbito do IFMG - Campus Piumhi, que resultem em ações que possam controlar as altas taxas de abandono e desistência dos cursos que ele oferece.

Palavras-chave: Evasão, Técnico em Edificações, educação.

\section{INTRODUÇÃO}

A evasão escolar, observada em todos os níveis de ensino, é um problema que atinge a maioria das instituições de ensino do país. Segundo Johann ${ }^{[7]}$, ela ocupa um espaço significativo no cenário das políticas educacionais e tem permeado diversos debates quanto à dificuldade de acesso e permanência dos estudantes nas instituições públicas brasileiras. ${ }^{1}$

Em 1995, a Secretaria de Educação Superior do Ministério da Educação e do Desporto - SESu/MEC propôs a criação de uma comissão composta por 
representantes indicados pelos dirigentes das Instituições Federais de Ensino Superior (IFES) e por representantes do então Ministério da Educação e do Desporto (MEC), que ficou encarregada de estudar em profundidade o tema da evasão, a fim de debater esta temática. Esta comissão recebeu o nome de Comissão Especial de Estudos sobre Evasão.

Com o apoio das Instituições de Ensino Superior Públicas (IESP), a comissão organizou um estudo, posteriormente divulgado como um relatório, que distingue a evasão de curso com base em diferentes situações, sendo estas: a não realização da matrícula, a desistência ou transferência de curso ou até mesmo o desligamento da instituição ou do sistema no qual o discente está matriculado. ${ }^{[8]}$

Estudos revelam que existem diversos motivos, internos e externos às instituições de ensino, que acarretam a evasão e que vão desde a infraestrutura escolar à problemas interpessoais com docentes e gestores da escola. Para $\mathrm{Cruz}^{[9]}$,a complexidade da vida pessoal, familiar, financeira e laboral também são fatores determinantes para esta decisão. ${ }^{3}$

Considerando esta pluralidade de causas, as especificidades de cada instituição e os impactos sociais e econômicos causados pelos índices cada vez maiores de evasão, torna-se necessário um debate sobre esta temática, através de uma análise quantitativa e qualitativa de dados que possa oferecer meios para sanar os problemas evidenciados e garantir a permanência do estudante no ambiente escolar.

Seguindo esta vertente, este artigo tem o intuito de traçar o perfil do estudante evadido no âmbito do curso Técnico em Edificações Subsequente do IFMG - Campus Piumhi, buscando entender e analisar as principais causas que contribuíram para a evasão, nestes casos e através dos resultados, propor políticas de permanência e apoio ao estudante propício ao abandono e desistência do curso.

Existem diversos trabalhos na literatura acadêmica que abordam esta temática. Campos e Santana ${ }^{[10]}$, por exemplo, analisam os principais fatores que contribuíram para a evasão escolar dos alunos do curso técnico subsequente de Manutenção e 
Suporte em Informática do IFS - Campus Itabaiana ${ }^{4}$. Cravo ${ }^{[11]}$ analisa as causas da evasão escolar do curso técnico de Informática em uma Faculdade de Tecnologia de Florianópolis ${ }^{5}$ e Meira ${ }^{[12]}$ apresenta um estudo de caso sobre a evasão escolar em um curso técnico profissionalizante do Instituto Federal do Espírito Santo. ${ }^{6}$

\section{REFERENCIAL TEÓRICO}

\subsection{TESTE EXATO DE FISHER}

O teste Exato de Fisher pode ser utilizado para verificar se há dependência ou não entre duas variáveis qualitativas, através da análise de tabelas de contingência utilizadas para registrar observações independentes de duas ou mais variáveis aleatórias. A estatística do teste se baseia no cálculo da distribuição de probabilidade das frequências dos elementos destas tabelas. A hipótese nula é de que não existe associação entre as variáveis ${ }^{[13]}$.

Em geral, para as análises envolvendo softwares especializados retornam um valor para a probabilidade de que a estatística do teste tenha valor extremo considerando o valor observado quando a hipótese nula é verdadeira. Esta probabilidade é denominada nível descritivo do teste (ou p-valor), cuja regra prática, considerando como nível de significância para o teste, é:

$$
\begin{gathered}
p-\text { valor } \leq \alpha \Rightarrow \text { Rejeita }- \text { se } H_{0} \Rightarrow \text { As variáveis não são independentes } \\
p-\text { valor }>\alpha \Rightarrow \text { Não Rejeita }- \text { se } H_{0} \Rightarrow \text { As variáveis são dependentes }
\end{gathered}
$$

De acordo com Melo e Rodrigues ${ }^{[14]}$, o p-valor é obtido diretamente, sem ser necessário o emprego de uma estatística intermediária, tornando mais fáceis as interpretações do pesquisador. ${ }^{8}$

\subsection{RAZÃO DE CHANCES}

A Razão de Chances (em inglês: Odds Ratio) é definida como a razão entre a chance de ocorrência de um evento em um grupo e outro. De acordo com Gujarati e 
Porter ${ }^{[15]}$ se um evento ocorre com probabilidade, a chance de ocorrência desse evento pode ser encontrada dividindo esta probabilidade pela probabilidade

$$
\text { chance }=\frac{p}{1-p}
$$

complementar. ${ }^{9}$ Matematicamente:

Dessa forma, se as probabilidades de ocorrência de um evento em dois grupos distintos forem (para o primeiro grupo) e (para o segundo grupo), então a razão de chances (OR) pode ser encontrada da seguinte forma:

$$
O R=\frac{\frac{p}{1-p}}{\frac{q}{1-q}}=\frac{p(1-q)}{q(1-p)}
$$

Segundo Szumilas ${ }^{[16]}$ trata-se de uma medida de associação entre uma exposição ao fator de risco e o caso controle, que simboliza a comparação entre as chances de ocorrer determinado resultado com a exposição ao fator de risco e a não exposição ao fator de risco e cuja classificação pode ser dada por:

$$
O R<1 \Rightarrow
$$
exposição tem menor possibilidade de ser um fator de risco para o resultado; $O R<1 \Rightarrow$ indica que a exposição não é um fator de risco para o resultado; $O R<1 \Rightarrow$ indica que a exposição tem maior possibilidade de ser um fator de risco para o resultado. ${ }^{10}$

Estudos que envolvem a razão de chances são muito frequentes nas áreas da saúde e sociais e tem ganhado cada vez mais espaço nas pesquisas das áreas das ciências humanas, pois através dela, além de identificar grupos mais prováveis de responderem a determinada tarefa é possível quantificar essa relação. 


\section{METODOLOGIA}

A metodologia constituiu-se, inicialmente, em uma revisão bibliográfica através da leitura de artigos, dissertações e teses, com o objetivo de apresentar um quadro geral sobre a problemática e assim auxiliar a compreensão acerca do tema.

Em seguida, foi realizado um estudo do tipo analítico-descritivo, através de dados quantitativos oriundos da Secretaria Acadêmica do IFMG - Campus Piumhi, coletados no decorrer do primeiro semestre de 2019. Nestas análises foram considerados todos os estudantes matriculados, evadidos e formados no curso Técnico em Edificações Subsequente durante o período compreendido entre 2014/2 e 2019/1.

Dentre os dados fornecidas, considerou-se mais relevantes para traçar o perfil do estudante evadido as variáveis: estado civil, sexo, procedência, idade, etnia, tipo de escola, tempo de formação no ensino médio, forma de ingresso no curso e renda familiar.

Com o auxílio dos softwares Excel e R (R Core Team, 2019), versão 3.5.3, construiuse tabelas de contingência e realizou-se o teste Exato de Fisher para verificar quais variáveis são significativas para determinar se o estudante tende ou não a evadir. Adotou-se 5\% como nível de significância e procedeu-se à análise da Razão de Chances para quantificar esta tendência.

Para ilustração, o Quadro 1 representa uma tabela de contingência construída buscando verificar se a evasão está relacionada ao estado civil do estudante (casado, solteiro ou divorciado). Cada célula do quadro indica o número de estudantes que se encontravam em determinada situação, ou seja, a frequência observada da realização simultânea das duas variáveis presentes no quadro (alunos evadidos e casados, ou não evadidos e solteiros, por exemplo).

Quadro 1- Dados para teste de independência

\section{EVADIDOS CASADOS SOLTEIROS DIVORCIADOS}




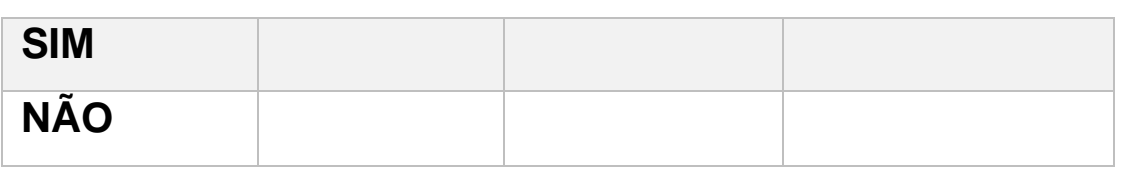

Fonte: Os Autores.

Também foram construídas tabelas de contingência para as variáveis o tempo de conclusão do ensino médio, tomando cinco anos como valor âncora, e renda familiar, considerando um salário mínimo como determinante. As demais variáveis não foram consideradas por não apresentarem nenhum indício de dependência, nas análises descritivas realizadas.

\section{RESULTADOS E DISCUSSÃO}

No período de 2014/2 até 2019/1 o índice de evasão no curso Técnico em Edificações Subsequente do IFMG - Campus Piumhi foi de 54,86\%, apontando para a urgência de discussões e debates sobre o tema. Desse percentual, cerca de $90 \%$ ingressaram através de vestibular, como ilustra o Gráfico 1 . Os demais $10 \%$ foram selecionados através de um sorteio que ocorreu em 2018 para completar as vagas não preenchidas pelo exame seletivo daquele ano. O Gráfico 2 refere-se ao estado civil desses estudantes. Observe que $78 \%$ dos estudantes evadidos são solteiros, $17 \%$ são casados e apenas $5 \%$ são divorciados.

Gráfico 1- Análise descritiva da variável Forma de Ingresso.

\section{Forma de Ingresso}

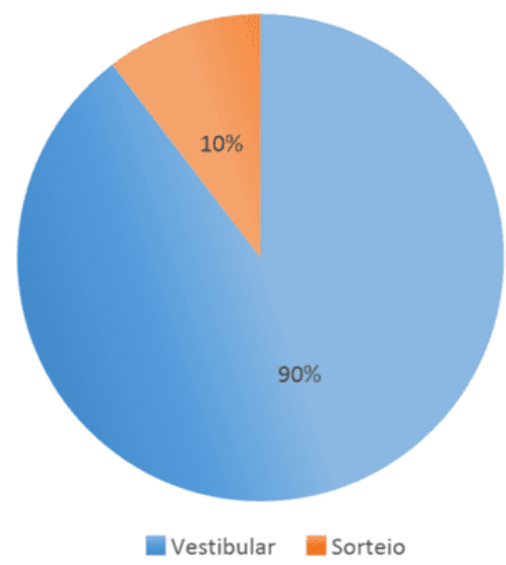


Fonte: Secretaria Acadêmica - IFMG Campus Piumhi

Gráfico 2- Análise descritiva da variável Estado Civil.

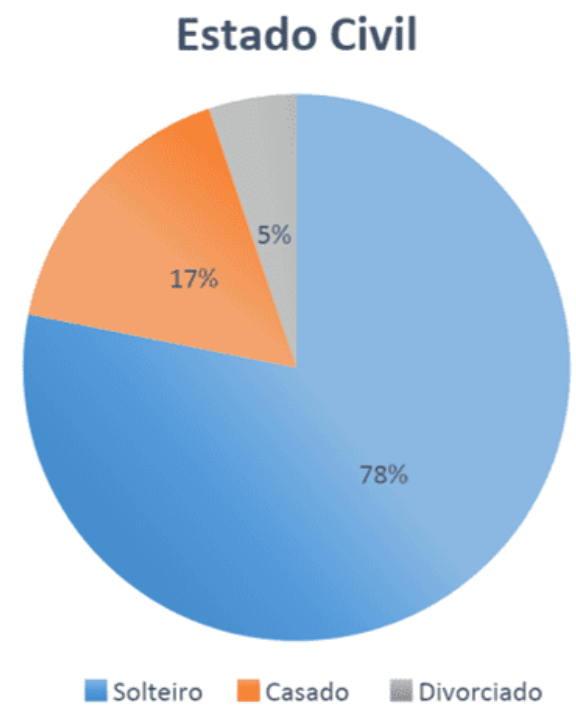

Fonte: Secretaria Acadêmica - IFMG Campus Piumhi

O Gráfico 3 mostra que cerca de dois terços dos estudantes evadidos são homens. O Gráfico 4 aponta para a procedência urbana de $96 \%$ dos estudantes evadidos.

Gráfico 3- Análise descritiva da variável Sexo.

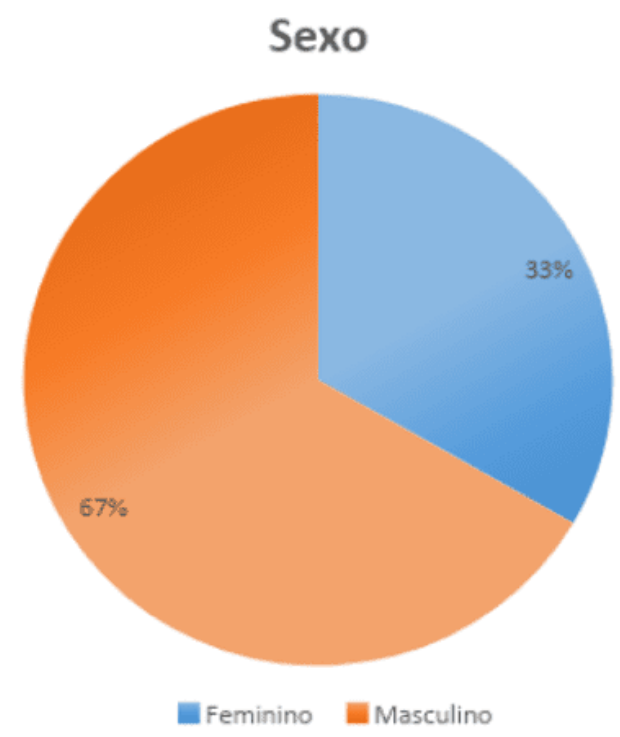

Fonte: Secretaria Acadêmica - IFMG Campus Piumhi. 
Gráfico 4- Análise descritiva da variável Procedência.

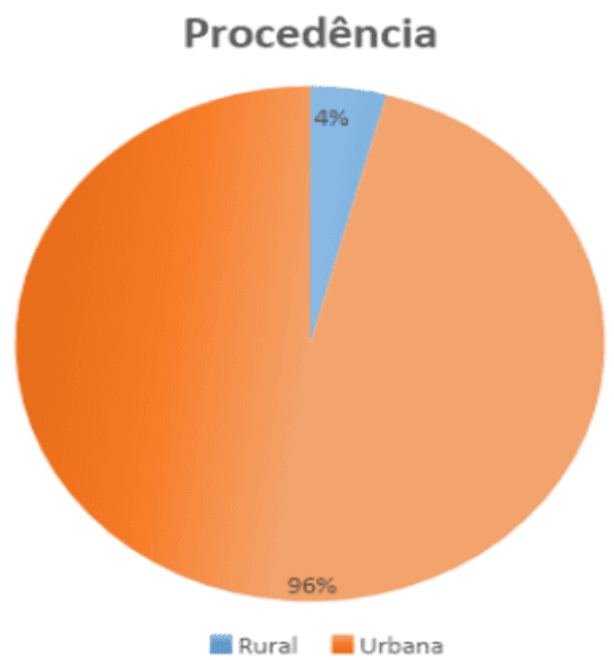

Fonte: Secretaria Acadêmica - IFMG Campus Piumhi

Analisando o gráfico 5 nota-se que 52\% dos estudantes evadidos são brancos, 33\% são pardos, $11 \%$ são pretos e os demais $4 \%$ se subdividem nas etnias amarela e indígena ou não quiseram informar.

Gráfico 5- Análise descritiva da variável Etnia.

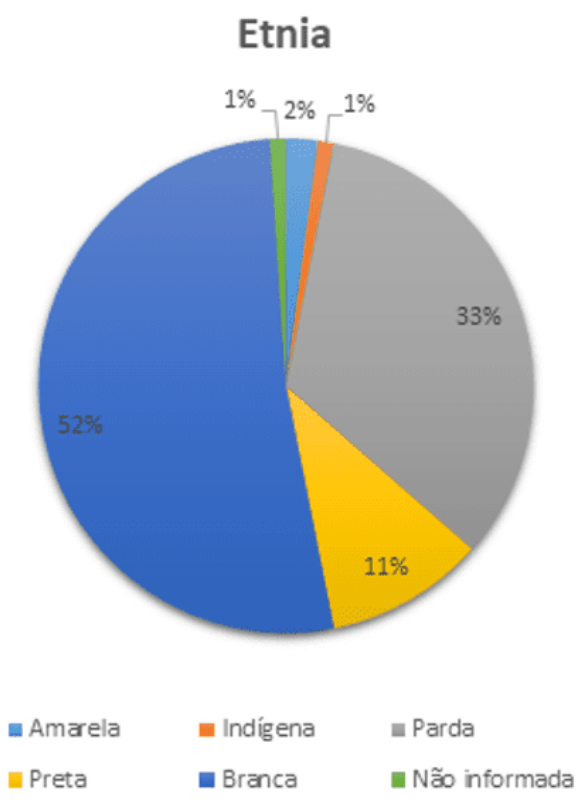

Fonte: Secretaria Acadêmica - IFMG Campus Piumhi 
Para analisar a variável idade, construiu-se um Boxplot, representado pelo Gráfico 6, que indica a dispersão desses dados. A mediana obtida foi de 27 anos e as idades tiveram limitantes inferior e superior iguais a 19 e 48 anos, respectivamente. Observe também a presença de um outlier cuja idade foi de 49 anos.

Gráfico 6- Análise descritiva da variável Idade.

\section{Boxplot para a variável Idade}

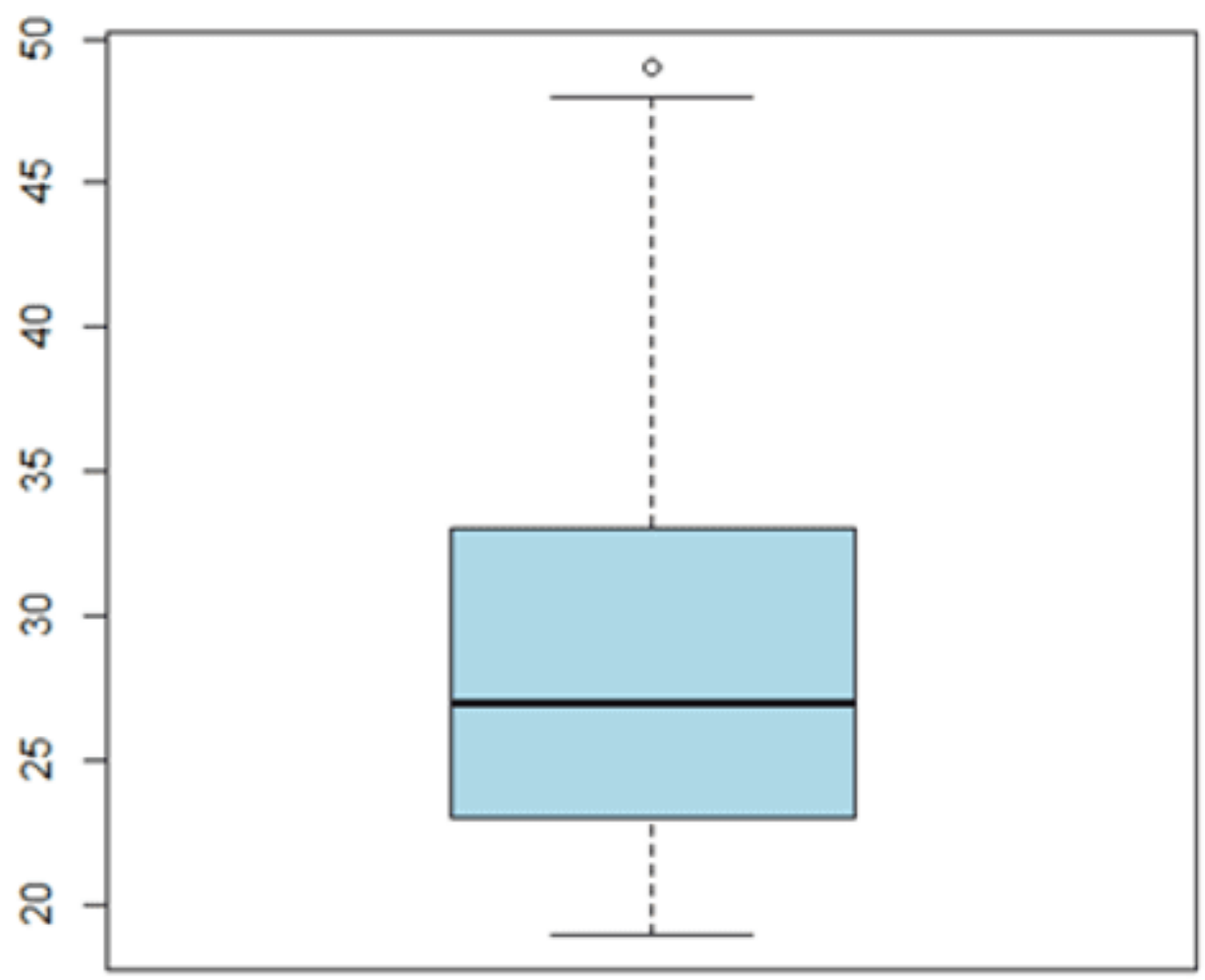

Fonte: Secretaria Acadêmica - IFMG Campus Piumhi

Ao analisar a independência pelo teste Exato de Fisher, verificou-se que apenas a variável tempo de conclusão do ensino médio foi significativa ( $p$-valor $=0,0016)$. Para esta variável, o odds ratio calculado foi de 3,736, ou seja, um estudante que concluiu o ensino médio a mais do que cinco anos têm chance 3,736 vezes maior de evasão no curso. As variáveis: estado civil $(p$-valor $=0,4123)$ e renda familiar $(p$-valor $=$ $0,4188)$ não apresentaram evidências de significância estatística. 
O Gráfico 7 traz a porcentagem de alunos evadidos em cada período analisado. Podese perceber que houve períodos em que a taxa de evasão foi nula e a maior taxa ocorreu no período 2016/2, sendo este valor 18,75.

Gráfico 7- Análise dos alunos Evadidos por Período.

\section{EVADIDOS POR PERIODO}

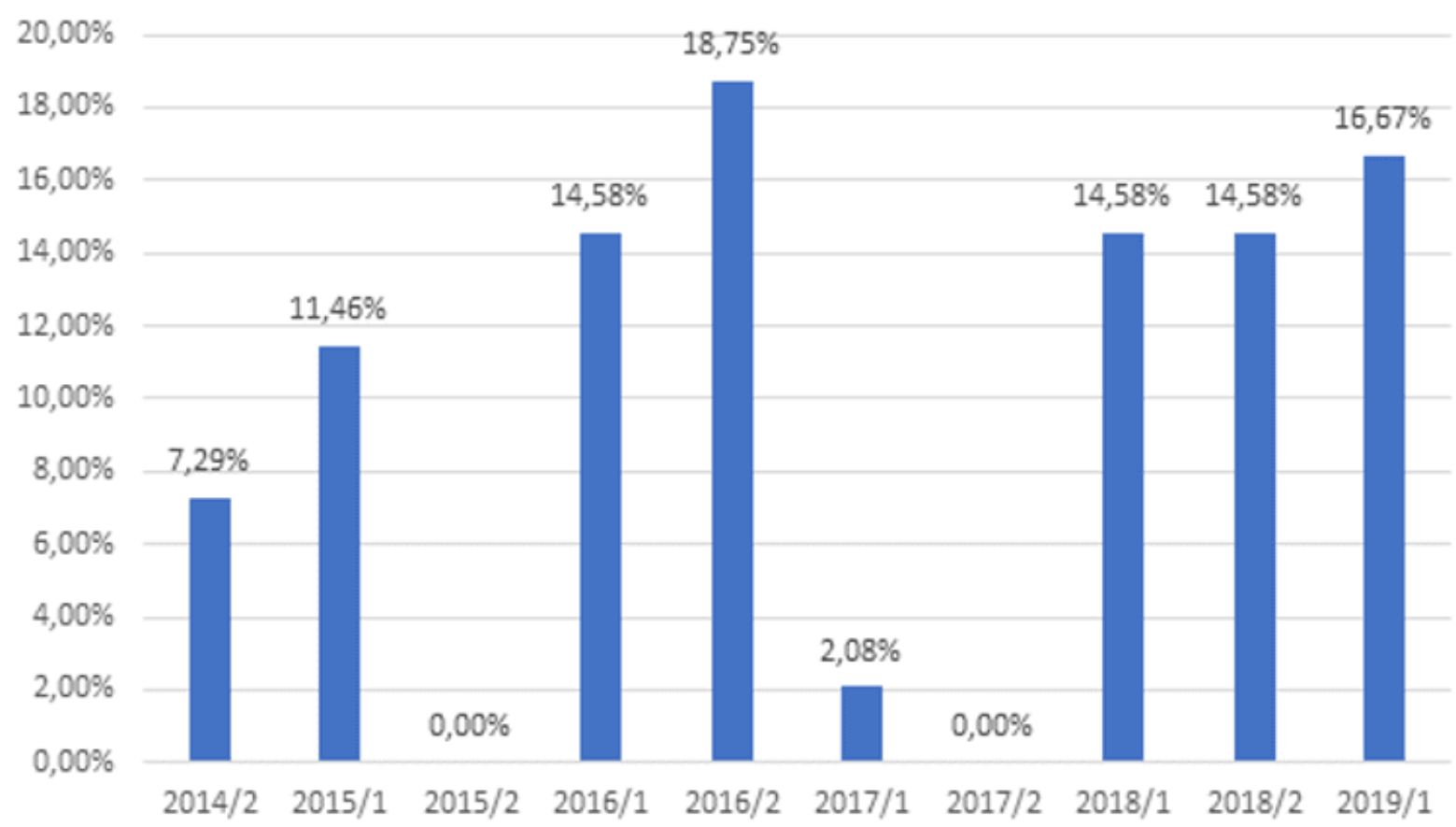

Fonte: Secretaria Acadêmica - IFMG Campus Piumhi

O Gráfico 8 mostra a porcentagem de alunos que formaram em cada período analisado. Nota-se que o período no qual houve maior quantidade de estudantes formados foi $2017 / 1$ (58,62\%) e o que teve menor número foi $2017 / 2(3,45 \%)$. 
Gráfico 8- Análise dos alunos Formados por Período.

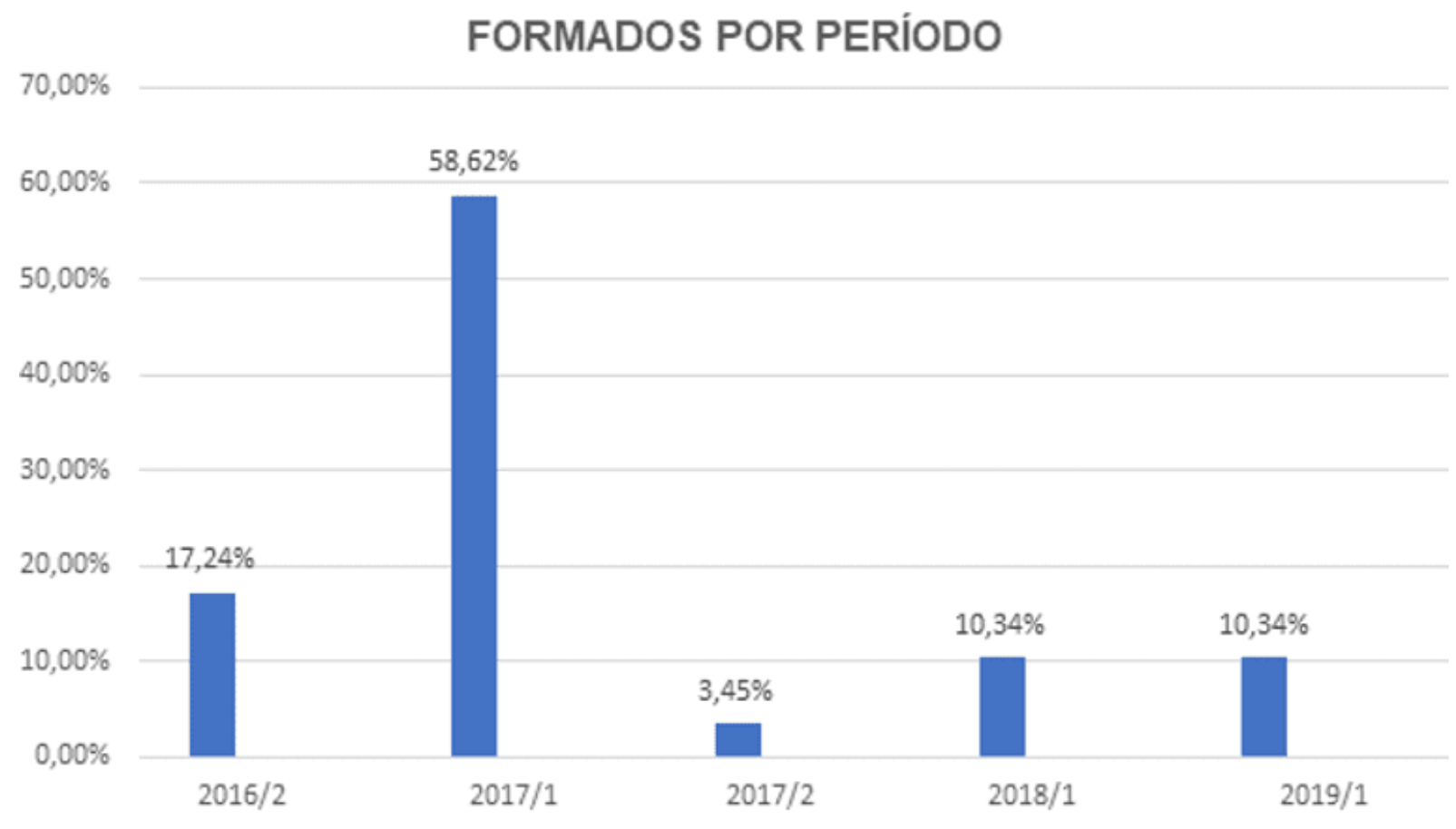

Fonte: Secretaria Acadêmica - IFMG Campus Piumhi

\section{CONCLUSÃO}

Este artigo apresentou os resultados de uma pesquisa introdutória cujo objetivo foi o de traçar o perfil do estudante evadido do curso Técnico em Edificações Subsequente do IFMG -Campus Piumhi. As análises realizadas e os resultados evidenciam a seriedade do problema enfrentado. Os alarmantes índices de evasão e os baixos índices de sucesso acadêmico evidenciam que algo precisa ser feito em caráter de urgência para contornar esta situação.

O estudo não foi aprofundado e não foi possível analisar as razões individuais que levaram os estudantes à evadirem, pois não houve um contato direto com eles, considerando que, por motivos éticos, não foram obtidos seus dados pessoais. Entretanto, este estudo confirmou o quão complexo e abrangente é o problema da evasão por ela ser "silenciosa" e pela pluralidade de suas causas que podem estar ligadas a fatores internos e externos ao ambiente escolar. 
Trata-se de um problema que precisa ser discutido e combatido com medidas preventivas que que possibilitem a integração do aluno no espaço formativo do IFMG. Acredita-se que possa ajudar no combate à evasão: a criação de um restaurante universitário (visto que o custo para a alimentação dos alunos seria menor), a melhoria das políticas de assistência estudantil (devido a diversidade de renda dos alunos e das condições menos favoráveis de alguns), o crescimento da oferta de monitoria aos estudantes (uma vez que se o aluno tiver concluído o ensino médio à um tempo expressivo, pode ser que tenha uma maior dificuldade nas disciplinas do curso), auxílio pedagógico e psicológico, cursos de nivelamento, entre outras.

Espera-se que este trabalho sirva como difusor dessas ideias e tragam para si um debate sobre as possíveis causas e consequências da evasão, tornando o ambiente escolar mais inclusivo e trazendo ganhos significativos para os processos de ensinoaprendizagem em todos os níveis de ensino ofertados pelo Campus Piumhi, onde as análises apresentadas foram executadas.

\section{REFERÊNCIAS}

ANDIFES/ABRUEM/SESU/MEC. Comissão Especial Sobre a Evasão nas Universidades Públicas Brasileiras. Diplomação, retenção e evasão nos cursos de graduação em instituições de ensino superior públicas, Brasília, 1996. 35f. p.16. Disponível em: <http://www.andifes.org.br/wpcontent/files_flutter/Diplomacao_Retencao_Evasao_Gr aduacao_em_IES_Publicas-1996.pdf> Acesso em: 17 jul. 2019.

CAMPOS, Geraldo Maia. Estatística prática para docentes e pós-graduandos, São Paulo: Faculdade de Odontologia de Ribeirão Preto, 2001. p.59. Disponivel em: <https://edisciplinas.usp.br/pluginfile.php/3223131/mod_folder/content/0/Estat\%C3\% ADstica\%20Pr\%C3\%A1tica\%20para\%20Docentes\%20e\%20P\%C3\%B3s.pdf?forced ownload=1> Acesso em: 17 jul. 2019

CAMPOS, Rafaely Karolynne Nascimento.; SANTANA, Gilvan Costa. Fatores e motivos da evasão escolar no curso técnico subsequente de Manutenção e Suporte 
em Informática do IFS - Campus Itabaiana, 2013. 11f. Disponível em: <http://educere.bruc.com.br/arquivo/pdf2013/8938_5032.pdf > Acesso em: 17 jul. 2019.

CRAVO, Ana Cristina. Análise das causas da evasão escolar do curso técnico de Informática em uma Faculdade de Tecnologia de Florianópolis, Revista Gestão Universitária na América Latina - GUAL, vol. 5, núm. 2, agosto-, 2012, pp. 238-250 Universidade Federal de Santa Catarina, Santa Catarina, Brasil. Disponível em: <https://www.redalyc.org/pdf/3193/319327515014.pdf> Acesso em: 27 ago. 2019

CRUZ, Anderson Paulo. Evasão nos cursos técnicos profissionais: uma análise das principais causas e identificação de perfil dos alunos evadidos do Senac Sete Lagoa, 2013. 91 f. Dissertação (Mestrado Profissional em Administração) - Fundação Pedro Leopoldo, Pedro Leopoldo, 2013. p. 25-38. Disponível em: <https://fpl.edu.br/2018/media/pdfs/mestrado/dissertacoes_2013/dissertacao_anders on_paulo_da_cruz_2013.pdf> Acesso em: 17 jul. 2019

GUJARATI, Damodar N.; PORTER, Dawn C. Econometria Básica, 5 ed. Porto Alegre: McGraw Hill, 2011. 924 p.

JOHANN, Cristiane Cabral. Evasão escolar no Instituto Federal Sul-rio-grandense: um estudo de caso no Campus Passo Fundo, 2012. 119 f. p. 10. Dissertação (Mestrado em Educação) - Universidade de Passo Fundo, Passo Fundo 2012. Disponível em: <http://tede.upf.br/jspui/handle/tede/739> Acesso em: 19 jul. 2019

MEIRA, Cristiane Araújo, A evasão escolar no Ensino Técnico Profissionalizante: um estudo de caso no Campus Cariacica do Instituto Federal do Espírito Santo, 2015.118f. Dissertação (Mestrado Profissional) - Universidade Federal do Espírito Santo, Vitória 2015. em: <http://portais4.ufes.br/posgrad/teses/tese_9068_Disserta\%E7\%E30\%20Final\%20\%20Cristiane\%20Meira.pdf> Acesso em 19 jul. 2019

MELO, Carolina Lima Gomes; RODRIGUES, Rodrigo Lins. Análise de relação entre variáveis de ocorrências de crimes da cidade do Recife, Revista de Engenharia e 
Pesquisa Aplicada, v. 3, n. 3, 30 ago. 2018. Disponível em: <http://revistas.poli.br/index.php/repa/article/download/943/442/> Acesso em: 26 ago. 2019

SZUMILAS, Magdalena. Explaining Odds Ratios. J Can Acad Child Adolesc Psychiatry, 19 ago. 2010. 3f. p 1.Disponível em: <https://pdfs.semanticscholar.org/d3f0/04464a83dc9cb9c354b6b2d9a0087c8a550a. pdf $>$ Acesso em 30 ago. 2019

\section{APÊNDICE - REFERÊNCIAS DE NOTA DE RODAPÉ}

7. JOHANN, Cristiane Cabral. Evasão escolar no Instituto Federal Sul-rio-grandense: um estudo de caso no Campus Passo Fundo, 2012. 119 f. p. 10. Dissertação (Mestrado em Educação) - Universidade de Passo Fundo, Passo Fundo 2012. Disponível em: <http://tede.upf.br/jspui/handle/tede/739> Acesso em: 19 jul. 2019

8. ANDIFES/ABRUEM/SESu/MEC. Comissão Especial Sobre a Evasão nas Universidades Públicas Brasileiras. Diplomação, retenção e evasão nos cursos de graduação em instituições de ensino superior públicas, Brasília, 1996. 35f. p.16. Disponível em: <http://www.andifes.org.br/wpcontent/files_flutter/Diplomacao_Retencao_Evasao_Graduacao_em_IES_Publicas1996.pdf > Acesso em: 17 jul. 2019.

9. CRUZ, Anderson Paulo. Evasão nos cursos técnicos profissionais: uma análise das principais causas e identificação de perfil dos alunos evadidos do Senac Sete Lagoa, 2013. 91 f. Dissertação (Mestrado Profissional em Administração) - Fundação Pedro Leopoldo, Pedro Leopoldo, 2013. p. 25-38. Disponível em: <https://fpl.edu.br/2018/media/pdfs/mestrado/dissertacoes_2013/dissertacao_anders on_paulo_da_cruz_2013.pdf>Acesso em: 17 jul. 2019

10. CAMPOS, Rafaely Karolynne Nascimento; SANTANA, Gilvan Costa. Fatores e motivos da evasão escolar no curso técnico subsequente de Manutenção e Suporte em Informática do IFS - Campus Itabaiana, 2013. 11f. Disponível em: 
<http://educere.bruc.com.br/arquivo/pdf2013/8938_5032.pdf > Acesso em: 17 jul. 2019.

11. CRAVO, Ana Cristina. Análise das causas da evasão escolar do curso técnico de Informática em uma Faculdade de Tecnologia de Florianópolis, Revista Gestão Universitária na América Latina - GUAL, vol. 5, núm. 2, agosto-, 2012, pp. 238-250 Universidade Federal de Santa Catarina, Santa Catarina, Brasil. Disponível em: <https://www.redalyc.org/pdf/3193/319327515014.pdf> Acesso em: 27 ago. 2019

12. MEIRA, Cristiane Araújo. A evasão escolar no Ensino Técnico Profissionalizante: um estudo de caso no Campus Cariacica do Instituto Federal do Espírito Santo, 2015.118f. Dissertação (Mestrado Profissional) - Universidade Federal do Espírito Santo, Vitória 2015.2 Disponível em: <http://portais4.ufes.br/posgrad/teses/tese_9068_Disserta\%E7\%E30\%20Final\%20\%20Cristiane\%20Meira.pdf> Acesso em 19 jul. 2019

13. CAMPOS, Geraldo Maia. Estatística prática para docentes e pós-graduandos, São Paulo: Faculdade de Odontologia de Ribeirão Preto, 2001. p.59. Disponivel em: <https://edisciplinas.usp.br/pluginfile.php/3223131/mod_folder/content/0/Estat\%C3\% ADstica\%20Pr\%C3\%A1tica\%20para\%20Docentes\%20e\%20P\%C3\%B3s.pdf?forced ownload=1> Acesso em: 17 jul. 2019

14. MELO, Carolina Lima Gomes; RODRIGUES, Rodrigo Lins. Análise de relação entre variáveis de ocorrências de crimes da cidade do Recife, Revista de Engenharia e Pesquisa Aplicada, v. 3, n. 3, 30 ago. 2018. Disponível em: $<$ http://revistas.poli.br/index.php/repa/article/download/943/442/> Acesso em: 26 ago. 2019

15. GUJARATI, Damodar N.; PORTER, Dawn C. Econometria Básica, 5 ed. Porto Alegre: McGraw Hill, 2011. 924 p.

16. SZUMILAS, Magdalena. Explaining Odds Ratios. J Can Acad Child Adolesc Psychiatry, 19 ago. 2010. 3f. p 1.Disponível em: 
<https://pdfs.semanticscholar.org/d3f0/04464a83dc9cb9c354b6b2d9a0087c8a550a. pdf> Acesso em 30 ago. 2019

Enviado: Dezembro, 2019.

Aprovado: Janeiro, 2020. 